\title{
Epidemiological analysis of spatially misaligned data: a case of highly pathogenic avian influenza virus outbreak in Nigeria
}

\author{
O. A. Adegboye and D. Kotze
}

\section{Summary}

This research is focused on the epidemiological analysis of the transmission of the highly pathogenic avian influenza (HPAI) $\mathrm{H}_{5} \mathrm{~N} 1$ virus outbreak in Nigeria. The data included 145 outbreaks together with the locations of the infected farms and the date of confirmation of infection. In order to investigate the environmental conditions that favoured the transmission and spread of the virus, weather stations were realigned with the locations of the infected farms. The spatial KolmogorovSmirnov test for complete spatial randomness rejects the null hypothesis of constant intensity $(P<$ 0.0001). Preliminary exploratory analysis showed an increase in the incidence of $\mathrm{H}_{5} \mathrm{~N} 1$ virus at farms located at high altitude. Results from the Poisson log-linear conditional intensity function identified temperature (-0.9601) and wind speed (0.6239) as the ecological factors that influence the intensity of transmission of the $\mathrm{H}_{5} \mathrm{~N} 1$ virus. The model also includes distance from the first outbreak (-0.9175) with an Akaike's Information Criterion of -103.87 . Our analysis using a point process model showed that geographical heterogeneity, seasonal effects, temperature, wind as well as proximity to the first outbreak are very important components of spread and transmission of HPAI H5N1.

\section{Introduction}

The World Health Organization (WHO) has described avian influenza as an infectious disease of animals (usually birds and less commonly pigs) caused by type A strains of the influenza virus. The main reservoir of the virus is wild birds and in the last two decades it has been seen in commercial and domestics poultry in Asia and Africa. Few cases of transmissions to humans and other mammals have also been documented by the United States Centers for Disease Control and Prevention, and the WHO. This virus was first reported in one state in Nigeria in 2006. The disease spread to 25 states and the Federal Capital Territory (FCT) within weeks [1]. The epidemic of $\mathrm{H}_{5} \mathrm{~N} 1$ has huge socioeconomic consequences with respect to animal welfare, international trade and cost. The federal government set aside the sum of 1.5 billion Naira (11.5 million US\$) for compensation alone for suspected birds that were culled throughout the nation to contain the spread of the disease. An economic impact assessment made by the Poultry Association of Nigeria (PAN) put the loss to farmers in the first 4 weeks of the outbreak to $14 \cdot 4$ billion Naira, which does not include those very small-scale farmers whose stock constitutes over $60 \%$ of the total national poultry population [2]. The consequence of the outbreak was devastating to the poultry owners as well as the consumer. 
The initial boycott of chicken and eggs created high demand and pressure on the supply of fish and other meat products. Outbreaks of highly pathogenic avian influenza (HPAI) had been confirmed in some parts of Africa: Benin, 2007, 2008; Burkina Faso, 2006; Cameroon, 2006; Cote d'Ivoire, 2006; Djibouti, 2006, 2007; Egypt, 2006, 2007, 2008; Ghana, 2007; Nigeria, 2006, 2008, 2009; Niger, 2006; South Africa, 2006, 2011, 2012; Sudan, 2006, 2007; Togo, 2007, 2008, 2009 [3]. Despite the spread and incidence of $\mathrm{H}_{5} \mathrm{~N} 1$, some farmers did not believe in its existence. This is very disturbing and may influence human infection [4]. Many studies have attributed the spread of $\mathrm{H}_{5} \mathrm{~N} 1$ virus in Nigeria and Africa to: international and interstate poultry trade $[4,5]$; as a result of regional influx of wild birds [4]; presence of visitors on farm premises, purchase of live poultry and poultry products by farmers, and farm workers living outside the farm premises [6]. Many households practised poultry farming at home (backyard) thereby increasing the risk of transmission of the avian virus to humans [7]. The management of backyard poultry farming has been identified as a challenge to the $\mathrm{H}_{5} \mathrm{~N} 1$ epidemic in Nigeria and improved biosecurity measures were advocated to prevent and control the spread of the disease [7]. In that study about onethird of the participants were aware of bird-to-man transmission of the avian virus and about two thirds were unaware of the existence of $\mathrm{H}_{5} \mathrm{~N} 1$ infection. The knowledge and awareness of avian flu and the risk of infection is low and hygiene is an important element to control the disease [7]. Three distinct waves of the $\mathrm{H}_{5} \mathrm{~N} 1$ epidemic in Nigeria were identified with peaks in January- March in the North West, North Central and North East and July-September in the South West and South South as well as disease clusters in the North West, North East and South West, respectively [8]. A previous analysis using the methods for spatial point processes with altitude as the only covariate in making inferences about $\mathrm{H}_{5} \mathrm{~N} 1$ outbreaks revealed a significant effect of altitude in estimating the pattern of $\mathrm{H}_{5} \mathrm{~N} 1$ virus [9].

It is difficult to describe the mechanism underlying the $\mathrm{H}_{5} \mathrm{~N} 1$ epidemic, and its origin, geographical, climatic and other factors that establish and influence the spread of the disease. Such difficulties can be a result of mismatch between data measured at different resolutions resulting in spatial misalignment [10]. Spatial misalignment of the exposure and response variables can bias the estimation of health risk [11]. The first major aim of this study was to realign the weather stations with the locations of the infected farms. The locations of the outbreaks of $\mathrm{H}_{5} \mathrm{~N} 1$ were not linked with the climate data measured at different weather stations. We considered the use of interpolation to estimate the weather data to provide a mean estimate for each infected farm. Moreover, possible association between $\mathrm{H}_{5} \mathrm{~N} 1$ outbreaks and environmental factors such as altitude, temperature, wind and dew were investigated. The geographical constraints that may favour the outbreak of the disease were explored to understand the effect of distances between farms. 


\section{Methods}

\section{Data source}

The data for this study consists of the HPAI $\mathrm{H}_{5} \mathrm{~N} 1$ outbreaks in 2006 that were reported to the World Organization for Animal Health (OIE) [3]. The information collected included the date of confirmation of infection (diagnosed), species, number of susceptible birds, number of infected birds and the locations of the infected farms (x,y coordinate system). The datasets can be found on the website of OIE [3]. Poultry farms (subsequently referred to as farms) in Nigeria are categorized as backyard flocks, which are normally comprised of a couple of dozen birds, and commercial poultry with up to hundreds of thousands of chickens. Figure 1 shows the locations of the infected farms which include cases from both commercial and backyard farms. The disease was either diagnosed using clinical signs or sent for a test at the national laboratory (National Veterinary Research Institute, Vom, Nigeria or the OIE's reference laboratory in Padova, Italy) [3]. A total of 145 diagnosed outbreaks were recorded; the first outbreak occurred on 10 January 2006 in Kaduna State, in the North-Western part of Nigeria. The virus spread to the central part of the country within weeks, and about 70\% of the total reported outbreaks occurred between January and March, 2006 (Fig. 2).

The climatic data for the available weather stations (see Fig. 1 for location of the weather stations) in Nigeria in 2006 were extracted from the National Climatic Data Centre of the National Oceanic and Atmospheric Administration, US Department of Commerce.

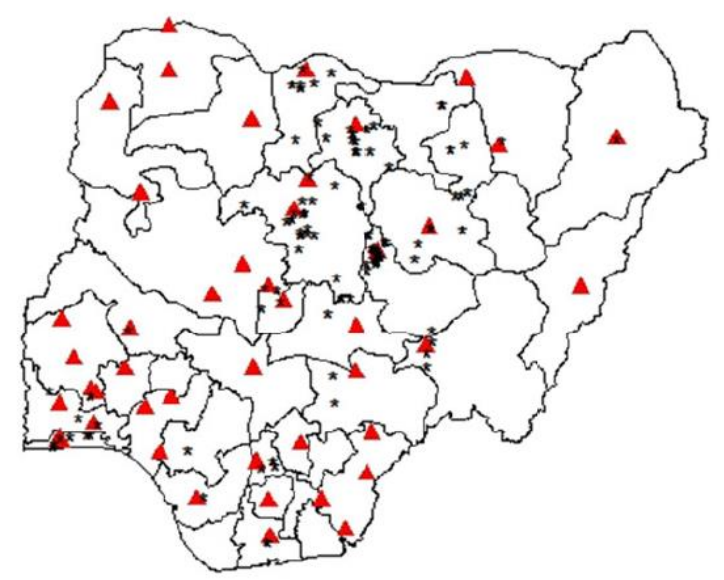

Fig. 1 [colour online]. The locations of HPAI H5NI virus-infected farms (black stars) and weather stations (red triangles). 


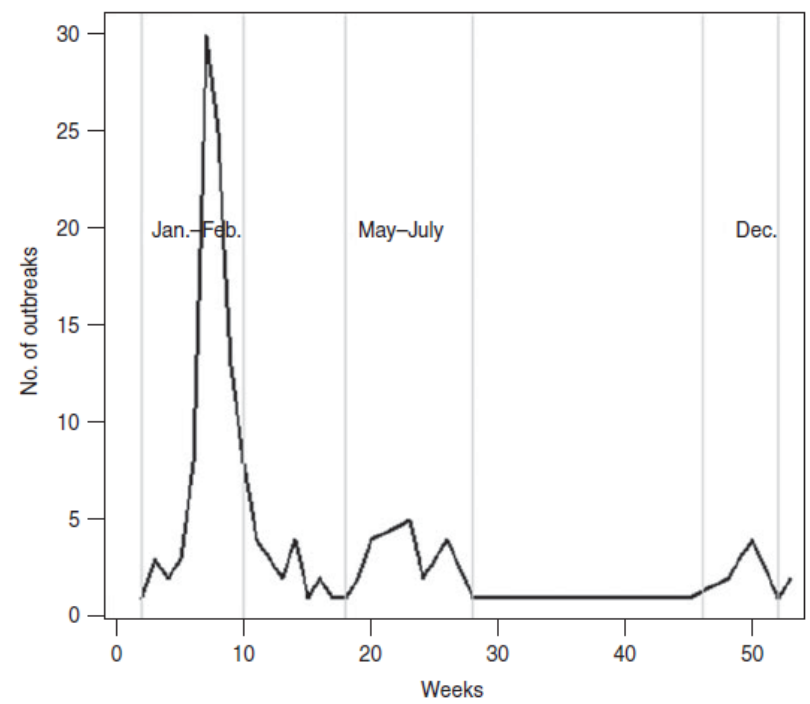

Fig. 2. Weekly number of cases of HPAI H5N1 since the beginning of the outbreak in Nigeria, January 2006.

Daily weather data were collected from 48 weather stations across Nigeria; these data included the temperature $\left({ }^{\circ} \mathrm{C}\right)$, dew point $\left({ }^{\circ} \mathrm{C}\right)$, wind speed (knots), pressure (millibars) and elevation (metres).

\section{Bayesian kriging}

Misalignment is often encountered in spatial analysis, this occurs when sampling at different spatial scales are not linked. In our case, the outbreaks of $\mathrm{H}_{5} \mathrm{~N} 1$ virus were not linked with the weather variables measured at different weather stations. One possible way to tackle this problem is through interpolation, a method of constructing new data points within the range of a discrete set of known data points.

Let $s i ; i=1,2, \ldots, N$, be the location of the infected farms and $Z(s l) ; l=1,2, \ldots, L$, the weather variables measured at the weather stations. Usually, we would want to measure these weather variables $\mathrm{Z}(\mathrm{sl})$ at the location of the infected farms, which involves the use of interpolation [12]. The spatial Gaussian process was assumed for the measured predictor and we constructed a conditional prediction of the predictors at the set location. The Gaussian process model was defined for the sets of weather stations, $\theta=(\psi, \tau)^{\prime}$ as the parameter vector. Let $\mathrm{Zs}{ }^{\prime}=\mathrm{Z}(\mathrm{s} 1), \ldots, \mathrm{Z}(\mathrm{sl}): \mathrm{Z}(\mathrm{sl}) \mid \alpha, \theta \sim \mathrm{N}(\mu, \Gamma)$, where $\mu \mathrm{sl}=(\mathrm{sl}, \alpha)$ is a predictor at the lth farm and $\Gamma$ is the spatial covariance matrix. Often, $\mu$ s will consist of trend surface components and $\Gamma l^{\prime}=\tau \rho\left(\mathrm{sl}-\mathrm{sl}^{\prime} ; \psi\right)$ (where $\tau$ is the variance and $\rho($.) is a correlation function for the Z's at the separation distance $\mathrm{sl}-\mathrm{sl}^{\prime}$ ). Using the conventional geostatistics approach for interpolation, i.e. 'kriging', the covariance structure is estimated first, then the estimated covariance is used for interpolation. The exponential form was used for $\rho\left(\mathrm{sl}^{-} \mathrm{sl}^{\prime} ; \psi\right)$ given by:

$$
\rho\left(s_{l}-s_{l^{\prime}} ; \psi\right)=\exp \left\{-\psi\left\|s_{l}-s_{l^{\prime}}\right\|\right\}
$$


where ||$s l-\mathrm{sl}^{\prime} \|$ is the Euclidean distance between farm $l$ and $l^{\prime}$. The Matérn function was used to estimate $\gamma(\mathrm{h}, \theta), \mathrm{h}=\mathrm{sl}-\mathrm{sl}^{\prime}$; given by

$$
\gamma(h, \theta)= \begin{cases}c_{0}+c_{h}\left[1-\frac{1}{2^{\alpha-1} \Gamma(\alpha)}\left(\frac{h}{a_{k}}\right)^{\alpha} K_{\alpha} \frac{h}{a_{k}}\right], & \text { if } h>0, \\ 0, & \text { if } h=0 .\end{cases}
$$

where $\theta=(\mathrm{co}, \mathrm{ck}, \mathrm{ak}, \alpha)$; c050, ck50, ak50, ${ }_{50}$ and $\mathrm{Ka}($.$) is the modified Bessel function of$ the second order of $\alpha$. Here, co measures the nugget effect and ck is the partial sill (so co+ck is the sill). As in the stable family, the behaviour near the origin is determined by $\alpha$, and the parameter ak controls the range. The behaviour of the semivariogram near the origin can be estimated from the data rather than assumed to be a certain form [13].

Bayesian kriging analysis was adopted for predicting a new set of locations $Z(\mathrm{si}) ; \mathrm{i}=1,2, \ldots$, $\mathrm{N}$. The posterior predictive distribution of $\mathrm{Z}(\mathrm{si})$ given the observations $\mathrm{Z}(\mathrm{sl})$ is

$$
f\left(Z\left(s_{i}\right) \mid Z\left(s_{l}\right)\right)=\int f\left(Z\left(s_{i}\right) \mid Z\left(s_{l}\right), \alpha, \theta\right) f\left(\alpha, \theta \mid Z\left(s_{l}\right) \partial \alpha \partial \theta,\right.
$$

where $f(\alpha, \theta \mid Z(s l))$ is the posterior of the model parameters.

The Matérn function [equation (2)] was implemented in geoR and the Bayesian analysis was implemented using the function krige.bayes [14]. Modelling $\mathrm{H}_{5} \mathrm{~N} 1$ intensity The variations of the disease intensity were measured by the inhomogeneous $\mathrm{K}$ function. In general, the intensity of a point process varies from place to place and the intensity function assumes that the expected number of points falls in a small area du around a location ui that satisfies $\mathrm{E}[\mathrm{N}(\mathrm{X} \cap \mathrm{B})]=\int \mathrm{B} \lambda(\mathrm{u}) \mathrm{du}$. The inhomogeneous $\mathrm{K}$ function stipulates that if $\lambda(\mathrm{u})$ is the true intensity function of the point process $X$, then each point xi will be weighted by wi $=1 / \lambda(u)$ :

$$
K_{\text {inhom }}(r)=E\left[\frac{1}{\lambda(u)} \sum_{x_{i} \in X} \frac{1}{\lambda\left(x_{i}\right)} 1\left\{0<\left\|u-x_{j}\right\| \leqslant r\right\} u \in X\right] \text {, }
$$

The space-time cluster interaction was measured at both the spatial and temporal scale using 
$K=\frac{L R}{n_{i} n_{j}} \sum \sum \frac{I_{h, t}\left(d_{i j}\right)}{w_{i j}}$,

where $n_{i}$ and $n_{j}$ are the numbers of observations within distance $h$ and time interval $t$ for the pair of events, respectively.

The spatial point process model was fitted to the data in which the point pattern is dependent on spatial covariates such as geographical location, week of infection, elevation, temperature, dew point and wind. The conditional intensity, presences per unit area [15], expressed as a log-linear function of the co-variates is

$$
\lambda(u)=\exp \left\{B^{\prime} Z(u)\right\}
$$

where $\beta$ is a vector parameter and $Z$ covariates at location $u$.

Akaike's Information Criterion (AIC) [16] was used to evaluate the 'goodness of fit' of each model. All data analyses were performed and implemented in R[17].

\section{Habitat suitability analysis (HSA)}

A HSA provides a way of modelling the relationship between species and habitat characteristics. The Habitat suitability index (HSI) describes the suitability of a given habitat by combining the interactions of all key environmental variables on a species' population characteristics and ultimately, survival [18]. Although the HSA is popular with species modelling, it is a growing area in spatial analysis of disease epidemiology that characterizes the distribution of the disease in a space defined by environmental parameters. The model can be constructed in several ways such as ecological niche analysis (ENA) which involves the use of geography and ecology of disease transmission [19] with the aim of determining the distribution of the species using the location where the species has been found [20].

Table 1. Percentage of HPAI H5N1 outbreaks in the five most affected states in Nigeria in 2006 and the duration of the outbreak

\begin{tabular}{lcc}
\hline \hline States & Cases $(\%)^{*}$ & Duration (days) $\dagger$ \\
\hline Plateau & $43(29 \cdot 7)$ & 143 \\
Kaduna & $18(12 \cdot 4)$ & 346 \\
Kano & $17(11 \cdot 7)$ & 346 \\
Bauchi & $17(11 \cdot 7)$ & 322 \\
Kastina & $9(6 \cdot 2)$ & 21 \\
\hline \hline
\end{tabular}

* Percentage of all cases; $28 \cdot 3 \%$ of cases in Nigeria occurred in other regions.

$\dagger$ Number of days from the first reported case to the last reported case. 
The idea is to use the observed presence (and absence) data together with ecological variables at those sites to provide a reasonable likelihood of the species being present [20]. Hirzel et al. [21] proposed ecological niche factor analysis (ENFA), a multivariate approach to study the geography of species distribution which does not require absence data. ENFA computes the suitability function by computing the species' distribution in the eco-geography variable space with that of the whole set of cells [22]. In this study, ENFA was used to compute the suitability function and produce the habitat suitability map for $\mathrm{H}_{5} \mathrm{~N} 1$, where the $\mathrm{HSI}$ values range from $\mathrm{O} \%$ to $100 \%$. HSI values close to $100 \%$ indicate an area where a species will flourish and values close to o imply an area where the species will not do very well. ENFA was performed using the 'enfa' function implemented in R [23].

\section{Results}

A high percentage of the outbreaks occurred in the Plateau State (29.7\%) followed by Kaduna State (12.4\%), Kano (11.7\%) and Bauchi (11.7\%) (Table1, Fig. 3). Preliminary exploratory analysis showed an increase in the incidence of $\mathrm{H}_{5} \mathrm{~N} 1$ virus at farms located at high altitude.

\section{Estimating weather variables}

A total of 48 weather stations across Nigeria were used for the interpolation of the weather data in this study. The location of the weather stations (black stars) and the infected farms (red triangles) are depicted in Figure 1. The occurrence of $\mathrm{H}_{5} \mathrm{~N} 1$ has been described to take place [8], with the suspicion of seasonal effects on the outbreaks (Fig. 2). This influence may be explained by some climatic variables and the disease epidemiology can be explored using ecological data. The weather stations were misaligned with the location of infected farms. The first task was to realign the weather stations. Interpolation was used to estimate the mean weather variables (temperature, wind, dew) for the infected farms (Fig. 4). Daily data were not available for some weather stations and thus weekly average weather predictions were used.

Different parametric models were fitted to the empirical semivariogram estimated to the data and the best fit model (Matérn) was chosen by varying the parameters. The estimated Bayesian variograms were checked against the empirical variogram by plotting the posterior distribution means, medians and modes. Histograms of the posterior distribution for the model parameters indicated a good fit of the Bayesian kriging prediction of the weather variables for the locations of infected farms (data not shown).

\section{H5N1 risk factors}

The spatial Kolmogorov-Smirnov test for complete spatial randomness rejects the null hypothesis of constant intensity with $P<0 \cdot 0001$. This implies that the locations of outbreaks are dependent on each other and that propensity varies from location to location (inhomogeneous). The inhomogeneous $K$-function plot shows that estimates of $K(r)$ using different techniques are roughly the same (Fig. 5). This suggests that $\mathrm{H}_{5} \mathrm{~N} 1$ outbreaks appear to be clustered after accounting for temperature, elevation, dew, wind and distance from the first outbreak. These covariates were used to fit a full inhomogeneous Poisson process intensity model. Using the method of backward elimination, the model with temperature, wind and distance

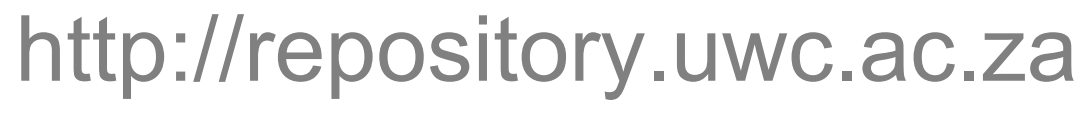


was found to best fit the data and to be suitable for predicting the intensity of a $\mathrm{H}_{5} \mathrm{~N} 1$ outbreak with an AIC of $-103 \cdot 87$.

Results from the Poisson point process model with a $1 \mathrm{~km} \times 1 \mathrm{~km}$ regular grid of quadrature points showed a negative effect of temperature and distance. This suggests that for a unit increase in temperature and distance from the first outbreak, the intensity of the transmission (number of outbreaks per unit area) of a $\mathrm{H}_{5} \mathrm{~N} 1$ outbreak decreases by $0 \cdot 9601$ and $0 \cdot 9175$, respectively.

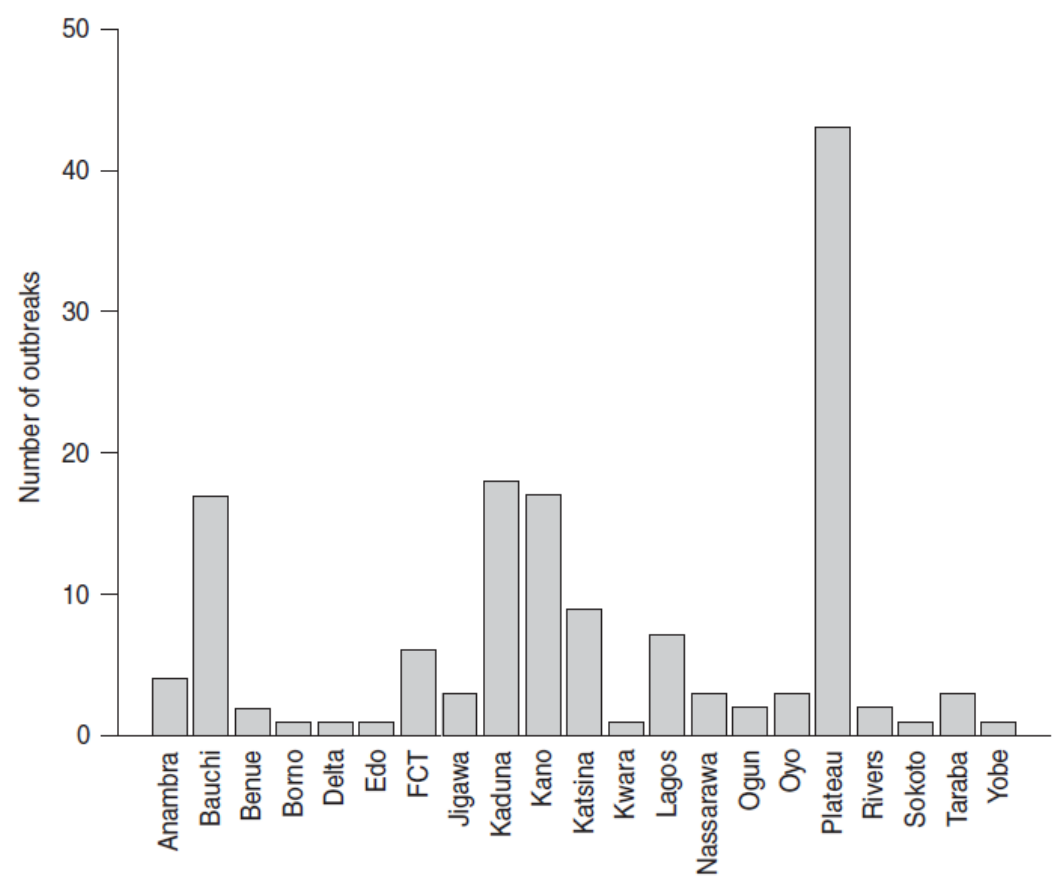

Fig. 3. Cases of HPAI H5N1 virus outbreak in Nigeria in 2006.

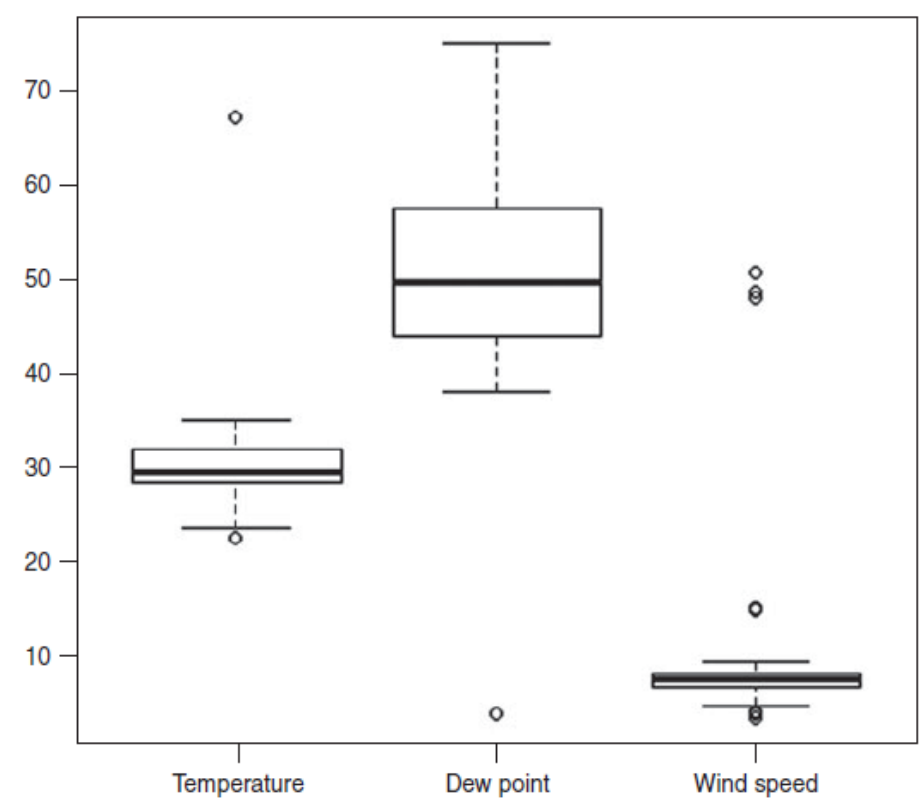

Fig. 4. Box plots of the predicted weather variables. 
The result shows that an increase in wind speed will increase the conditional intensity of the disease outbreak. Moreover, the negative effect of distance on the intensity of the transmission implied that an increase in the distance results in a decrease in the intensity of the transmission of the virus. Figure 6 presents the intensity of the transmission of $\mathrm{H}_{5} \mathrm{~N} 1$ virus using the Poission process model; the fitted model exhibits similar patterns in the transmission of the virus as the observed $\mathrm{H}_{5} \mathrm{~N} 1$ outbreak. The intensity of the transmission (indicated by different colours in Fig. 6) suggest that most of the infected farms are located in the North Central region of Nigeria and occurred within a short time frame.

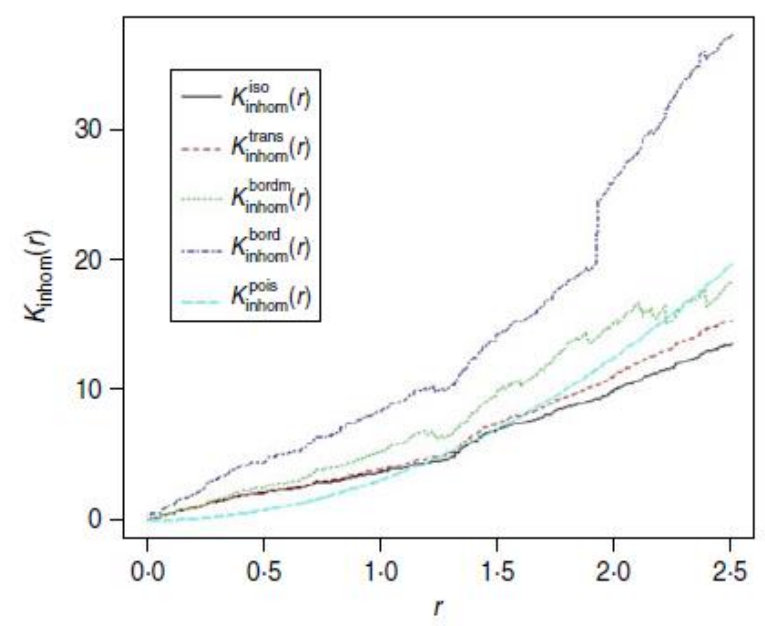

Fig. 5 [colour online]. $K$-inhomogeneous functions using different edge corrections: theoretical Poisson, border-corrected estimate, translation-corrected estimate, and Ripley's isotropic correction estimate.

The habitat suitability map for the disease is presented in Figure 7; higher HSI values were observed around the northern part of the country (60-100\%); this implies that the $\mathrm{H}_{5} \mathrm{~N} 1$ virus is favoured by the climatic condition in the North Central region of Nigeria and areas in close proximity to the first outbreak.

\section{Discussion and conclusion}

It is difficult to describe the mechanism underlying the $\mathrm{H}_{5} \mathrm{~N} 1$ epidemic, its origin, and the geographical, climatic and other factors that establish and influence the spread of disease. Information on the spread of infectious diseases is crucial for control and surveillance initiative programmes. The role played by weather variables in the transmission and spread of HPAI should not be overlooked. The $\mathrm{H}_{5} \mathrm{~N} 1$ virus was found to be a result of regional influx of wild birds [4], migratory waterfowl [24, 25], trade routes [26] and also the effect of transportation of farm staff and poultry products [6,27]. Our results showed that the spread and transmission of HPAI $\mathrm{H}_{5} \mathrm{~N}_{1}$ is favoured by some weather variables and areas in close proximity to the first outbreak. 
The movement of people, equipment and animals within infected farms may contribute to the spread of the pathogen. Airborne transmission of the pathogen may also occur through dust and feathers. This method of transmission has been previously studied [28-31]; these studies attest to our findings suggesting that there is a relationship between the intensity of the disease in a given region and, wind speed and temperature. The contribution of wind in the transmission of the pathogens has been described as occurring only in short distances and the extent may be relatively small [30, 31]. Although the effect of biosecurity has been discussed in another paper [7], temperature and wind may induce dryness of the environment which may in turn make it easier for the virus to be transmitted between birds. Moreover, the effect of alternating temperature highs and lows may imply seasonality that could alter the transmission and survivability of the virus, which is consistent with the temporal patterns observed by Ekong et al. [8]. These authors suggest that the outbreak occurred in different waves. Brown \& Rohani [32] have studied the effect of alteration between migratory shorebird and horseshoe crabs as a result of climate change.
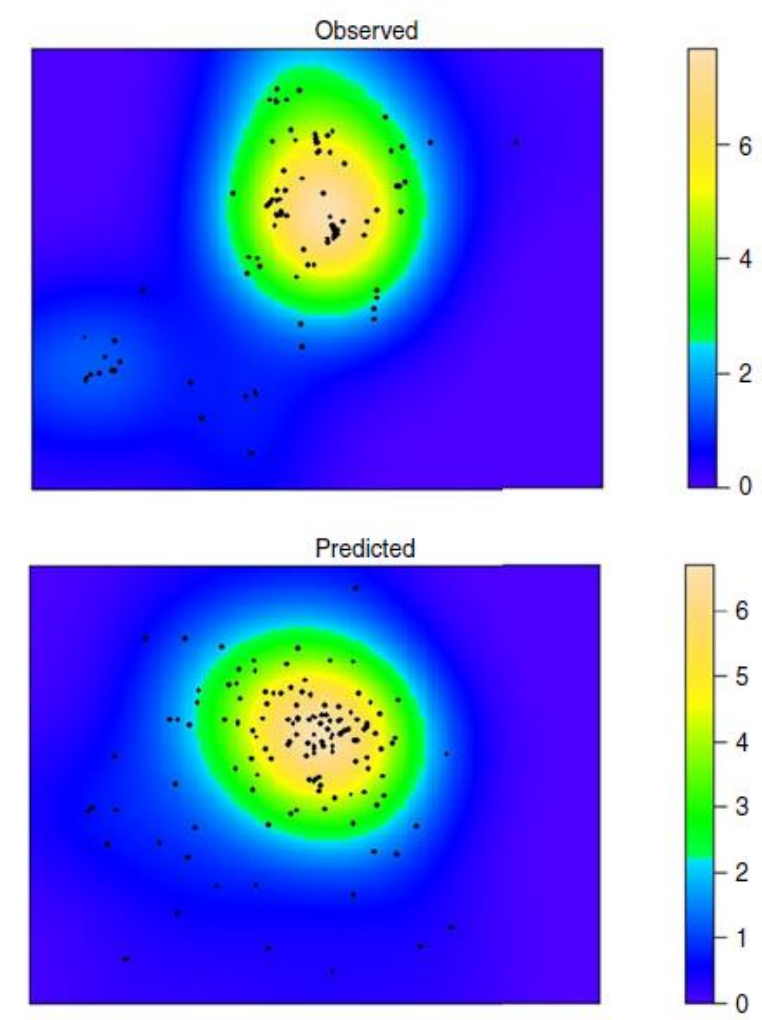

Fig. 6 [colour online]. HPAI H5N1 risk map from Poisson point process model with log-linear intensity. The intensity of the transmission of the virus (i.e. the number of outbreaks per unit area) is indicated by different colours with values ranging from 0 to 8 . 


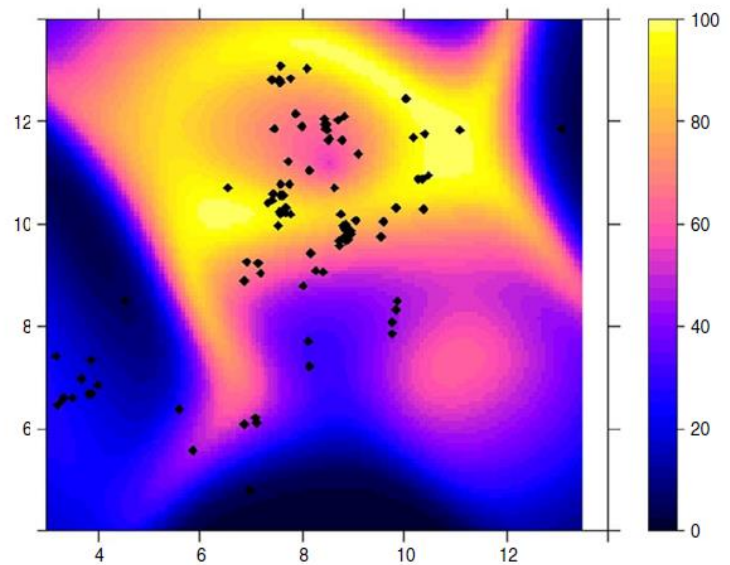

Fig. 7 [colour online]. Habitat suitability index $(0-100 \%)$ for HPAI H5N1 virus outbreak in Nigeria using the predicted weather data as environmental covariates.

Vandegrift et al. also reviewed how anthropogenic change may alter the evolution and transmission of influenza viruses [33]. The initial outbreak of the disease in Nigeria was attributed to the movement of migratory birds [34]; this supports our findings of wind as a risk factor because the wind speed and direction may also affect the path of migratory birds thereby altering the spread of the virus.

This study provides empirical analysis of how spatial models can be used to capture the intensity and mechanism of the spread of $\mathrm{H}_{5} \mathrm{~N} 1$ virus with misaligned weather data. The application of the Bayesian kriging method to predict weather variables in a misaligned dataset was demonstrated. These techniques were applied to the HPAI $\mathrm{H}_{5} \mathrm{~N} 1$ virus outbreak in Nigeria in 2006. The spatial Poisson process intensity fitted as a log-linear function has shown that intensity combined with temperature, wind and distance from the first outbreak provides a better estimate. A HSA was conducted using ecological niche modelling on the point process and the predicted weather data, to explore the habitat suitability of $\mathrm{H}_{5} \mathrm{~N} 1$ and to predict the geographical distribution of the disease outbreak.

The major limitation of this study lies in the data gathering and risk factors. The data on HPAI $\mathrm{H}_{5} \mathrm{~N} 1$ virus were only extracted from the OIE database and cases of underreporting cannot be ruled out. Moreover, Nigeria is a very large country with very poor data acquisition and the lack of e-data sources may affect timely reporting of disease occurrence. It would be interesting to be able to have additional variables linked to the location of events (e.g. those that address biosecurity, farm characteristics, and measure virus dispersion). This study only considered the ecological aspect of disease transmission due to availability of data. Furthermore, we could not assess the extent (distance) of the contribution of the wind in the transmission of HPAI based on limited data. In spite of these limitations, OIE provides very reliable and considerable data that yielded extensive information crucial for HPAI analysis in Nigeria. The analysis based on these data offers the opportunity to detect whether environmental and ecological variables are potential risk factors for the mapping of suitable habitats.

Our analysis using point process modelling also showed that geographical heterogeneity and seasonal effects are very important components of the spread and transmission of HPAI $\mathrm{H}_{5} \mathrm{~N} 1$. 
The study calls for adequate surveillance and quick quarantine of infected farms in close proximity to the first outbreak. Further studies could incorporate and utilize the wind direction and dust dispersion (as proxy for airborne dispersion of the virus), farm population density and biosecurity in determining the pattern and mechanism of the spread of disease.

\section{Acknowledgements}

We are grateful to Olalekan Adetunji for technical help on Bayesian kriging. The authors express their profound gratitude to the reviewer for helpful comments and constructive criticism.

\section{Declaration of interest}

None. 


\section{References}

1. Ojo O. The economic effect of avian influenza in poultry in South-West Nigeria (dissertation). Ibadan, Oyo, Nigeria: University of Ibadan, 2008, $74 \mathrm{pp}$.

2. Duru JA. Avian influenza outbreak in Nigeria: The farmers experience. Animal Production Research Ad vances 2006; 2: 129-133.

3. Organization for Animal Health database (http://www.oie.int/animal-health-in-theworld/update-on-avian-influenza/2006/). Accessed 11 April 2013.

4. Fasina FO. Molecular and spatial-temporal epidemiology of highly pathogenic notifiable avian influenza $\mathrm{H}_{5} \mathrm{~N} 1$ in Nigeria (dissertation). Pretoria: South Africa: University of Pretoria, 2008, $157 \mathrm{pp}$.

5. Bello M, Lukshi BM, Sanusi M. Outbreaks of highly pathogenic avian influenza $\left(\mathrm{H}_{5} \mathrm{~N}_{1}\right)$ in Bauchi State, Nigeria. International Journal of Poultry Science 2008; 7: 450-456.

6. Fasina FO, et al. Identification of risk factors associated with highly pathogenic avian influenza $\mathrm{H}_{5} \mathrm{~N} 1$ virus infection in poultry farms, in Nigeria during the epidemic of 20062007. Preventive Veterinary Medicine 2011; 98: 204-208.

7. Musa O, et al. Community awareness of bird flu and the practice of backyard poultry in a North-Central state of Nigeria. Journal Preventive Medicine Hygiene 2010; 51: 146-151.

8. Ekong PS, et al. Spatio-temporal epidemiology of highly pathogenic avian influenza $\left(\mathrm{H}_{5} \mathrm{N1}\right)$ outbreaks in Nigeria, 2006-2008. Preventive Veterinary Medicine 2012; 103: 170177 .

9. Adegboye OA. Spatio-temporal analysis of transmission of avian flu outbreak in Nigeria. Proceedings of the 25th International Biometric Conference, Santa Catarina, Brazil, 2010. 10.Banerjee S, Carlin BP, Gelfand AE. Hierarchical Modelling and Analysis for Spatial Data. Boca Raton: Chapman and Hall/CRC, 2004.

11. Peng R, Bell M. Spatial misalignment in time series studies of air pollution and health data. Biostatistics 2010; 11: 720-740.

12.Lawson A. Hierarchical Modelling in Spatial Epidemiology. Florida: Chapman and Hall/CRC Press, 2008.

13. Waller L, Gotway C. Applied Spatial Statistics for Public Health Data. New York: John Wiley and Sons, 2004.

14. Ribeiro P, Diggle P. geoR: a package for geostatistical analysis. $R$ News 2001, pp. 14-18.

15. Cressie NAC. Statistics for Spatial Data. New York: John Wiley \& Sons, 1993.

16. Burnham KP, Anderson DR. Model Selection and Multimodel Inference: A Practical Information-Theoretic Approach. New York: Springer, 2002.

17. R Development Core Team. R: A Language and Environment for Statistical Computing. Vienna, Austria: R Foundation for Statistical Computing, 2006 (http:// www.Rproject.org).

18.Atlantic Ecology Division. (http://www.epa.gov/aed/ html/research/scallop/hsi.html). Accessed 7 February 2013.

19. Peterson A. Ecologic niche modelling and spatial patterns of disease transmission. Emerging Infectious Diseases 2006, 12: 1822-1826.

20. Fischer D, Thomas SM, Beierkuhnlein C. Modelling climatic suitability and dispersal for disease vectors: the example of a phlebotomine sandfly in Europe. Procedia EnvironmentalSciences 2011; 7: 164-169. 
21. Hirzel AH, et al. Ecological-niche factor analysis: how to compute habitat-suitability maps without absence data? Ecology 2002; 83: 2027-2036.

22. Arnese A. Applying ecological niche factor analysis for predicting modelling in the Kaulonia field survey. Proceedings of the 35th International Conference on Computer Applications and Quantitative Methods in Archaeology. Berlin, Germany, 2007, 428 pp.

23. Basille $\mathrm{M}$, et al. Assessing habitat selection using multivariate statistics: some refinements of the ecological-niche factor analysis. Ecological Modelling 2008; 211: 233240.

24. Hanson B, et al. Avian influenza viruses and paramyxoviruses in wintering and resident ducks in Texas. Journal of Wildlife Diseases 2005; 41: 624-628.

25. Krauss $\mathrm{S}$, et al. Influenza A viruses of migrating wild aquatic birds in North America. Vector-Borne Zoonotic Disease 2004; 4: 177-189.

26. Gilbert $\mathrm{M}$, et al. Anatidae migration in the western palearctic and spread of highly pathogenic avian influenza $\mathrm{H}_{5} \mathrm{~N} 1$ virus. Infectious Disease 2006; 12: 1650- 1656.

27. Oyana T, Dai D, Scott K. Spatiotemporal distributions of reported cases of the avian influenza $\mathrm{H}_{5} \mathrm{~N} 1$ (bird flu) in Southern China in early 2004. Avian Diseases 2006; 50: 508515 .

28. Spekreijse D, et al. Airborne transmission of a highly pathogenic avian influenza virus strain $\mathrm{H}_{5} \mathrm{~N} 1$ between groups of chickens quantified in an experimental setting. Veterinary Microbiology 2011; 152: 88-95.

29. Sander $\mathrm{H}$, et al. Airborne transmission of influenza $\mathrm{A} / \mathrm{H}_{5} \mathrm{~N} 1$ virus between ferrets. Science 2012: 336; 1534- 1541.

30.Ssematimba A, Hagenaars TJ, de Jong MCM. Modelling the wind-borne spread of highly pathogenic avian influenza virus between farms. PLoS One 2012; 7(2).

31. Mikkelsen T, et al. Investigation of airborne foot-and-mouth disease virus transmission during low-wind conditions in the early phase of the UK 2001 epidemic. Atmospheric Chemistry Physics 2003; 3: 2101-2110.

32. Brown VL, Rohani P. The consequences of climate change at an avian influenza 'hotspot'. Biology Letters 2012; 8: 1036-1039.

33. Vandegrift KJ, et al. Ecology of avian influenza viruses in a changing world. Annals of the New York Academy of Sciences 2010; 1195: 113-128.

34.Fasina FO, et al. Molecular characterization and epidemiology of the highly pathogenic avian influenza $\mathrm{H}_{5} \mathrm{~N} 1$ in Nigeria. Epidemiology Infection 2009; 137: 456463. 